\section{The Role of Layout in Improving Building Thermal Performance in Bangkok}

\section{Thanun Srithongchai}

Faculty of Architecture, Khon Kaen University, 40002, Thailand, Thanunsri@kku.ac.th, Thanun_Srithongchai@hotmail.com

*Corresponding author: Thanunsri@kku.ac.th

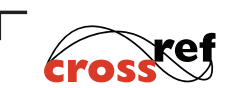

http://dx.doi.org/10.5755/j01.sace.29.2.29410
Selecting a building layout is a fundamental task in the early stage of the architectural design process. High thermal mass buildings with well-insulated envelopes are a common solution for colder climates; however, thinner wall construction and lower mass in most tropical architecture means that a welldesigned building layout with good consideration of contextual factors is essential to enhance passive cooling and to decrease heat gain by solar radiation. Building layout factors of perimeter and wall surface area are pivotal in long-term energy utilization. This simulation-based research employs Sketchup, Openstudio, and SPSS to investigate the effect of surface solar radiation on indoor air temperature and sensible cooling energy of 17 geometries with and without a self-shading feature under the identical space volume, floor area, and climatic conditions of Bangkok. The simulation conducted in two phases (with and without an active cooling system) revealed that the lower the F/W ratio is, the lower the $\mathrm{DBT}_{\text {indoor-annual }}$ and operational cost of the $\mathrm{A} / \mathrm{C}$ system. The circular plan with the highest $\mathrm{F} / \mathrm{W}$ ratio $(0.47)$ has the lowest annual wall solar heat gain and $\mathrm{DBT}_{\text {indoor-annual }}\left(29.43^{\circ} \mathrm{C}\right)$, and saves approximately $10 \%$ of air cooling energy demand compared to the square design ( $F / W=0.42)$. The layouts with $\mathrm{S} / \mathrm{W}$ ratio less than 2.4 are less effective in lowering the $\mathrm{DBT}_{\text {indoor-annual }}$ and active cooling energy demand than those with $\mathrm{S} / \mathrm{W}$ greater than 2.4 . It is concluded that the self-shading designs $(\mathrm{S} / \mathrm{W}<2.4)$ may face challenges due to greater wall surface area and receiving more diffuse solar radiation.

Keywords: building energy, building simulation, EnergyPlus, building geometry, self-shading design.

Thermal comfort is an essential attribute of indoor thermal quality that ensures human health and wellbeing in the use of buildings. Fanger (1970) identified six influential thermal comfort factors, four of which relate to environmental aspects: dry bulb temperature, humidity, air velocity, and radiant temperature. Building designers persevere to improve their designs with close consideration of such factors to create environments conducive to the wellbeing and comfort of building users. Building form, which is the most fundamental passive design solution, can affect energy use in buildings regarding lighting and air-conditioning systems. Interest in building form and zoning has been of great concern in energy-efficient building research. The amount of energy used in a building varies according to its geometry (Parasonis, Keizikas, and Kalibatiene 2012, Hatem and Karram 2020). Thick and tall geometries, known as internal load dominated (ILD) (Fosdick and Homes 2016), require more energy for lighting systems due to limited wall surface area. This type of buildings require cooling energy all year, due to heat generated by the artificial lighting system. Conversely, skin load dominated (SLD) buildings have extensive wall surface area and longer building perimeter, and may demand a greater amount of energy from an HVAC system, and less energy for lighting.
JSACE $2 / 29$

\author{
The Role of Layout \\ in Improving \\ Building Thermal \\ Performance in \\ Bangkok
}

Received 2021/07/06

Accepted after revision 2021/09/27

\title{
Introduction
}

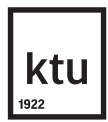

Journal of Sustainable Architecture and Civil Engineering Vol. 2 / No. 29 / 2021 pp. 189-204 DOI 10.5755/j01.sace.29.2.29410 
The impacts of building shapes on energy requirements have drawn research attention worldwide. Different climatic settings have been studied in the examination of building energy performance, using ratios invented as factors to analyze the effects of physical parameters such as window-towall ratio (WWR) (Jeyasingh and Sekar 2013, Susorova et al. 2013, Goia 2016, Zhang et al. 2017), building surface-to-volume (Su 2008), and floor-to-enclosure (Ferdous and Gorgolewski 2014). The WWR factor has been found to have a preeminent impact on building heat gain, since the glazing area is a more instrumental factor in solar heat gain than building geometry per se (Ferdous and Gorgolewski 2014, FSEC Energy Research Centre 2019).

Internal heat gain is generated from user activities, lighting, duct systems, and equipment. External heat gain infiltrates buildings from exterior environmental factors, particularly solar radiation on the building surface, especially due to fenestration (FSEC Energy Research Centre 2019). Building designers, especially in project design for hot climates, take heat gain by exterior surface into account as a core parameter, since this heat source leads to a direct and massive elevation of indoor temperature, and a requirement for cooling energy.

Solar heat protection by self-shading (using the building geometry for sun-shading) is a very attractive passive solution by which architects can reduce solar heat gain via building surfaces. Furthermore, fundamental passive design aspects and knowledge adopted from vernacular architecture are preferred in solutions to improve indoor living conditions. Traditional Thai houses were generally built according to a cluster design, assembling a set of living units built with wooden structures (typically bamboo), convenient for maintenance, earthquake resistance, and relocation (Panitchpakdi 2016). This vernacular architecture made ample use of primitive passive solutions, such as shading external open spaces and facilitating cross-ventilation to interior and exterior spaces.

Jitkhajornwanich (2001) and Chenvidyakarn (2007) recommended a passive design solution regarding the structure and building control to create a more comfortable indoor living environment focusing on six core aspects: orientation, building form, natural ventilation, solar control and application of shading devices, heat protection by vegetation, and material selection, color, and texture of building surface. Providing an area for a courtyard in buildings to facilitate such purposes has been of interest to building designers and researchers. The proportion and shapes of courtyards have drawn research attention, and a series of studies on this topic confirm that various configurations of courtyard proportions, building geometry, and shading solutions can vary the sunlit area of courtyards and affect the cooling or heating energy consumption of buildings (Soflaei et al. 2017, Al-Hafith et al. 2017).

The main aim of most modern researchers is to provide sustainable building solutions with reduced energy requirements to insure occupant comfort, and using geometric configurations (such as courtyards) as potential solutions. The study of full-scale buildings oriented along ordinal and cardinal axes with WWR, ranging from 0.12 to 0.3 under hot and humid climate of Chennai, India, demonstrated an impact of building orientation on indoor thermal condition (Jeyasingh and Sekar 2013).

Examining physical factors in actual buildings allowed researchers to observe real-time thermal behavior, but such methods are time-consuming, and incur considerable costs. Building energy modeling software is an alternative tool to allow designers to compare the applied energy-saving strategies and pre-evaluate the building energy performance before construction. Building Performance Simulation (BPS) tools have been developed for decision making by building designers and software developers during the schematic design process. Petersen and Purup (2019) developed a BPS tool integrating a set of software including Rhino/Grasshopper, DIVA, and ICEbear. Interviews with BPS users demonstrated that BPS tools can benefit building designers in the early design stage. Hatem and Karram (2020) investigated the impact of building forms on energy 
performance using DesignBuilder for ten geometries: circle, triangle, T-shape, L-shape, U-shape, square, courtyard, and rectangle 1:2, 1:3, and 1:4 (with different orientations, and with and without shading). Four cities in Egypt were studied, with the Cairo climate used as a reference due to the homogeneity of simulations. Triangular orientations with 0 and 135-degree rotations were found to be the most energy-saving layout, while the 90 and 315-degree rotations were the most energy-demanding, due to increased solar exposure of the wall area. Rectangular shapes were found to consume less energy than circular plans. The longitudinal shape laid along the east-west axis was the most energy-consuming. T, L, and U-shaped plans present a small impact on energy performance when rotated, yet demand a significant amount of energy. A courtyard, generally considered a suitable design for desert climates, presents an increase in energy consumption by $2.5 \%$ compared with the square design. Their study found differences in energy requirement of each building layout with different orientations. However, the volume and floor area, especially the roof surface of the buildings, were not controlled. These factors can vary the amount of direct solar radiation, which is the main cause of external heat gain via building external surfaces.

The effect of building forms on energy consumption was examined by previous studies under different climatic conditions. However, few studies have considered hot and humid tropical regions, including Thailand. While it is universally acknowledged that the glazed area of building surfaces (i.e., windows) is the main source of external heat gain in buildings, heat exchange through wall opaque surfaces in hot and humid climates is not well-understood in relation to different rates of heat gain, as most studies of wall material thermal properties have been conducted in Western/ non-tropical contexts. In colder climates, buildings are generally built with thick walls with high thermal mass, with air cavity and insulated materials to prevent heat loss (and, less importantly for temperate and colder climates, heat gain). Heat loss via wall surfaces is minimal, manageable, and of negligible concern in such contexts (FSEC Energy Research Centre 2019). However, this construction pattern, due to the climatic conditions, seems not to be commonly transferred to local buildings in Thailand, where lightweight materials are typically used in walls and roofs, which is recommended for local construction (Jitkhajornwanich 2001); consequently, small-domestic buildings in Thailand are generally built with noticeably thinner walls (typically of $100-\mathrm{mm}$ thickness). This practice results in low thermal mass, and thus minimal storage of heat and maximized capacity to release accumulated heat, but rendering the building more sensitive to external conditions compared to structures with higher thermal mass (i.e., more intense heat transfer to internal spaces during daylight hours, and faster cooling at night). External wall surface area varies according to building perimeter and layout, which influences building requirements.

Thus, this study aims to compare indoor temperature and sensible cooling energy of 17 basic building layouts using Sketchup modeler, OpenstudioThai version 1.7.0.7 thermal zone assignment, and Energyplus energy simulation. Wall surface area and sunlit areas were analyzed to examine how much solar radiation the surfaces of the models receive annually. The simulation was conducted in two phases: with and without $\mathrm{A} / \mathrm{C}$. The former phase examines the effect of exterior condition on indoor DBT, while the latter explores how much sensible cooling energy is required to condition the indoor air. The results are analyzed using Microsoft Excel and IBM SPSS version 22, and are discussed to reach some conclusions for practitioners and researchers.

This study examines the impacts of various building layouts on energy performance and indoor temperature. This research considers that observing and measuring actual constructions is ideal to allow researchers to extract real and precise results. However, such a procedure requires a period of experiment with a large amount of funding. This study employs building energy modeling software to investigate building thermal behavior and energy requirement. Al Ka'bi (2020) compared the capability of building energy simulation software which are EnergyPlus (the successor to DOE2.1E), DesignBuilder, IDA-ICE, IES-VE, TRNSYS, eQUEST, Auto-desk GBS, Ecotect, RIUSKA, and

\section{Methods}


VIP-Energy. TRNSYS, with its user-friendly interface, was found to be the most comprehensive software, including $91 \%$ of total variables, followed by Ecotect (85\%), Auto-desk GBS (82\%), and then EnergyPlus (79\%). However, the inhibitive expense of licenses for more comprehensive programs means that EnergyPlus version 9.5.0 remains the most widely used modelling tool for building thermal behavior and energy requirement for the $\mathrm{A} / \mathrm{C}$ system, offering competitive simulation

\begin{tabular}{|c|c|c|}
\hline lable 1 & Simulation Method & Input \\
\hline \multirow[t]{12}{*}{$\begin{array}{l}\text { Building setting and } \\
\text { configuration }\end{array}$} & $\begin{array}{l}\text { Site location } \\
\text { Latitude }\end{array}$ & $\begin{array}{l}\text { Bangkok } \\
13.92 \text { degree }\end{array}$ \\
\hline & Longitude & 100.6 degree \\
\hline & Time zone & $+7 \mathrm{hr}$ \\
\hline & Elevation & $12 \mathrm{~m}$ \\
\hline & Solar distribution & FulllnteriorAndExterior \\
\hline & Terrain & City \\
\hline & Weather data & THA_Bangkok.484560_IWEC.epw \\
\hline & Heat balance algorithm & ConductionTransferFunction \\
\hline & HVAC template: system & Unitary System \\
\hline & Cooling setpoint schedule & $25^{\circ} \mathrm{C}$ \\
\hline & Cooling design supply air temperature & $12.8^{\circ} \mathrm{C}$ \\
\hline & Cooling coil gross rated COP & $3 \mathrm{~W} / \mathrm{W}$ \\
\hline
\end{tabular}

strategies. The monthly average outdoor dry bulb temperature (DBT (RH $\left(\mathrm{RH}_{\text {outdoor }}\right)$. The monthly average DBT $\mathrm{Dutdor}_{\text {r }}$ ranges from $26.4^{\circ} \mathrm{C}$ in December to $30.6^{\circ} \mathrm{C}$ in April. The lowest and highest $\mathrm{RH}_{\text {outdoor-Av }}$ are $57.71 \%$ and $80.95 \%$ in December and October, respectively. For hourly data, the coldest and hottest hours are $15.3^{\circ} \mathrm{C}$ at 7:00 AM on the $25^{\text {th }}$ of January and $38.2^{\circ} \mathrm{C}$ at 4:00 PM on the $29^{\text {th }}$ of April. The highest and lowest $\mathrm{RH}$ magnitudes are $22.75 \%$ at 4:00 PM on $17^{\text {th }}$ of March and $98.88 \%$ at 7:00 AM on $23^{\text {rd }}$ of February, respectively. The maximum and minimum outdoor average wind velocities are $1.97 \mathrm{~m} / \mathrm{s}$ in January and $4.22 \mathrm{~m} / \mathrm{s}$ in June.

The simulation employs FullinteriorAndExterior, whereby the effect of beam radiation on the interior and exterior building surfaces are considered in the calculation. The software considers the sunlit area and the effect of building self-shading in relation to the geometries and sun position using the shadowing algorithms of TARP and BLAST. EnergyPlus considers the effect of solar gain on exterior surfaces $\left(Q_{s 0}\right)$, as presented in Eq. 1:

$$
Q s o=\alpha \cdot\left(l b \cdot \cos \theta \cdot \frac{S s}{s}+I s \cdot F s s+I g \cdot F s g\right)
$$

where $a$ is surface solar absorptance, $S$ is surface area, $S_{s}$ is the sunlit area, $I_{b}$ is the direct radiation intensity, $I_{s}$ is the sky diffuse radiation intensity, $I_{g}$ is the ground reflected diffuse radiation intensity, $F_{s s}$ is an angle factor between the surface and the sky $\left(F s s=\frac{1+\cos \theta}{2}\right)$, and $F_{s g}$ is the angle factor between the surface and the ground $\left(F s g=\frac{1-\cos \theta}{2}\right.$ ) (Liu et al. 2019). Further information on solar radiation issues can be found in Documentation Engineering Reference, available on the EnergyPlus official webpage (U.S. Department of Energy 2021).

The building geometries were generated in SketchUp 2017. The building surface thermal conditions and construction materials included an external wall, roof, and floor, as shown in Table 2, assigned by OpenstudioThai version 1.7.0.7 (DEDE.go.th 2017). The models were entirely built with opaque walls (without doors and windows), and the context of the simulation was in Bangkok, Thailand, with data input details as shown in Table 1. 


\begin{tabular}{l|c|c|c|c|c|c|}
\hline \multicolumn{7}{|c}{ Construction Details and Material Properties } \\
\hline \multirow{2}{*}{ Construction } & Layer & Material & $\begin{array}{c}\text { Thickness } \\
(\mathrm{mm})\end{array}$ & $\begin{array}{c}\text { Conductivity } \\
(\mathrm{W} / \mathrm{m} . \mathrm{K})\end{array}$ & $\begin{array}{c}\text { Density } \\
\left(\mathrm{kg} / \mathrm{m}^{3}\right)\end{array}$ & $\begin{array}{c}\text { Specific Heat } \\
(\mathrm{J} / \mathrm{kg} . \mathrm{K})\end{array}$ \\
\hline \multirow{2}{*}{ External Wall } & 1 & Plaster render & 10 & 0.24 & 800 & 840 \\
\cline { 2 - 8 } & 2 & $100 \mathrm{~mm}$ brick & 100 & 0.6 & 1300 & 900 \\
\hline & 3 & Plaster render & 10 & 0.24 & 800 & 840 \\
\hline Roof & 1 & 200 mm concrete slab & 200 & 1.7 & 2200 & 840 \\
\hline Floor & 1 & 200 mm concrete slab & 200 & 1.7 & 2200 & 840 \\
\hline
\end{tabular}

Table 2

Construction details and material properties

\section{Two Phases of Simulation}

This simulation was conducted in two phases with two different ventilation models (with and without an HVAC system), to compare cooling loads for each thermal zone. A unitary system was set to operate 24 hours throughout the year for each zone, with the thermostat set at a constant setpoint of $25.0^{\circ} \mathrm{C}$. No incidental infiltration and internal heat gains, such as those arising from building users, artificial lighting, and equipment, were assigned for the models.

\section{Model Geometries}

Geometries discussed in this study are selected based on simple shapes examined in previous studies (Ferdous and Gorgolewski 2014, Hatem and Karram 2020, Zhang et al. 2017) such as square, rectangular, triangle, L-shape, and circular floor plans are reviewed. Besides, the recent study also analyzes fundamental geometries which may not draw attention in the field such as pentagon, hexagon, and octagon layouts. Those simple shapes are compared with the self-shading design which are cluster and courtyard layouts for comparison purposes. The latter layout considered as a common technique for hot and humid climate which now is commonly applied in hot and humid region is included, while the former is known for its passive solution found in hot and humid region.

Finally, this study examines 17 layouts with floor plate area and space volume control factors of $100 \mathrm{~m}^{2}$ and $600 \mathrm{~m}^{3}$ (respectively), with 6.0-m height. The layouts are square, square with 45-degree rotation ( square $_{45}$ ), circle, I-shape on north-south axis $\left(\right.$ I-shape $\left._{\mathrm{N}-\mathrm{S}}\right)$, I-shape on east-west axis $\left(\right.$ I-shape $\left._{E-W}\right)$, L-shape on north-east axis $\left(L-\right.$ shape $\left._{N-E}\right)$, L-shape on east-south axis (L-shape $\left.E_{E-S}\right)$, L-shape on south-west axis $\left(\mathrm{L}_{-}\right.$shape $\left._{\mathrm{S}-\mathrm{w}}\right), \mathrm{L}$-shape on west-north axis $\left(\mathrm{L}-\right.$ shape $\left._{\mathrm{W}-\mathrm{N}}\right)$, golden proportion on north-south axis $\left(G_{\text {olden }} \mathrm{N}-\mathrm{S}\right.$ ), golden proportion on east-west axis (Golden $\mathrm{E}_{\mathrm{E}-\mathrm{w}}$ ), triangle, pentagon, hexagon, octagon, courtyard, and cluster.

For comparison purposes, the benchmark building is selected based on the following criteria:

1. A compact shape.

2. Each side of the wall must present an equal surface area to control the solar gain area on each side of the benchmark model.

3. The selected shape must be commonly found in small-scale buildings.

Based on these criteria, compact geometries with equal wall surface areas are in the shape of a triangle, square, pentagon, hexagon, or octagon. The square shape was selected as a benchmark model, since this simplest form is the most commonly used in small-scale constructions in Thailand.

All models were elevated $6 \mathrm{~m}$ away from the ground, to eliminate the effect of ground energy exchange by thermal conduction. The SketchUp models were converted to IDF format and were transferred to EnergyPlus for further simulation. A summary of building geometries and dimensions is illustrated in Fig. 1. 
Fig. 1

Summary of physical information of tested geometries

\begin{tabular}{|c|c|c|c|c|c|c|c|c|c|c|c|c|}
\hline \multirow[b]{2}{*}{ No. } & \multirow[b]{2}{*}{ Name } & \multirow[b]{2}{*}{ Isometric } & \multicolumn{4}{|c|}{ Dimensions } & \multirow[b]{2}{*}{$\begin{array}{l}\text { Volume } \\
\text { (cubic } \mathrm{m} \text { ) }\end{array}$} & \multirow[b]{2}{*}{$\begin{array}{c}\text { Floor Area } \\
\text { (sq.m) }\end{array}$} & \multirow[b]{2}{*}{$\begin{array}{l}\text { Floor to Wall } \\
\text { Area Ratio } \\
\text { (F/W) }\end{array}$} & \multirow[b]{2}{*}{$\begin{array}{l}\text { Total Exterior Wall } \\
\text { Surface Area (sq.m) }\end{array}$} & \multirow[b]{2}{*}{\begin{tabular}{|} 
Annual Exterior Wall \\
Sunlit Area (sq.m)
\end{tabular}} & \multirow[b]{2}{*}{\begin{tabular}{|c} 
Annual Exterior Wall \\
Sunlit Area to Wall \\
Area Ratio $(S / \mathrm{W})$
\end{tabular}} \\
\hline & & & $A(m)$ & $B(m)$ & $c(m)$ & $D(m)$ & & & & & & \\
\hline 1 & square & & 10.00 & $x$ & 6.00 & $x$ & 600.00 & 100.00 & 0.42 & 240.00 & 60.05 & 0.25 \\
\hline 2 & Squure (45") & & 10.00 & $x$ & 6.00 & $x$ & 600.00 & 100.00 & 0.42 & 240.00 & 60.09 & 0.25 \\
\hline 3 & \begin{tabular}{|l} 
l-shape (North to South) \\
(1-shapenss)
\end{tabular} & & 20.00 & 5.00 & 6.00 & $x$ & 600.00 & 100.00 & 0.33 & 300.00 & 75.05 & 0.25 \\
\hline 4 & $\begin{array}{l}\text { I-shape (East to West) } \\
\text { (li-shape ew) }\end{array}$ & & 2.00 & 20.00 & 6.00 & $x$ & 600.00 & 100.00 & 0.33 & 300.00 & 75.09 & 0.25 \\
\hline 5 & $\begin{array}{l}\text { L-shape (North to East) } \\
\text { (l-shapene) }\end{array}$ & & 12.50 & 7.50 & 6.00 & 5.00 & 600.00 & 100.00 & 0.33 & 300.00 & 71.60 & 0.24 \\
\hline 6 & \begin{tabular}{|l} 
L-Shape (Eass to South) \\
(ll-shapesu)
\end{tabular} & & 12.50 & 7.50 & 6.00 & 5.00 & 600.00 & 100.00 & 0.33 & 300.00 & 71.60 & 0.24 \\
\hline 7 & $\begin{array}{l}\text { L-shape (South to West) } \\
(1-\text {-Shapesw) }\end{array}$ & & 12.50 & 7.50 & 6.00 & 5.00 & 600.00 & 100.00 & 0.33 & 300.00 & 71.40 & 0.24 \\
\hline 8 & \begin{tabular}{|l} 
L-shape (West to North) \\
(l-shapewewn)
\end{tabular} & & 12.50 & 7.50 & 6.00 & 5.00 & 600.00 & 100.00 & 0.33 & 300.00 & 71.37 & 0.24 \\
\hline 9 & $\begin{array}{l}\text { Golden proportion (North } \\
\text { to south) } \\
\text { Golden proportionns }\end{array}$ & & 12.75 & 7.86 & 6.00 & $x$ & 600.00 & 100.00 & 0.40 & 247.00 & 61.79 & 0.25 \\
\hline 10 & $\begin{array}{l}\text { Golden proportion (Esst to } \\
\text { west) } \\
\text { solden proportiontw }\end{array}$ & & 7.86 & 12.75 & 6.00 & $x$ & 600.00 & 100.00 & 0.40 & 247.00 & 61.81 & 0.25 \\
\hline 11 & circular & & 5.64 & $x$ & 6.00 & $x$ & 594.00 & 99.00 & 0.47 & 212.10 & 53.10 & 0.25 \\
\hline 12 & Triangle & & 15.20 & $x$ & 6.00 & $x$ & 600.00 & 100.00 & 0.37 & 273.60 & 69.46 & 0.25 \\
\hline 13 & Pentagon & & 7.62 & $x$ & 6.00 & $x$ & 600.00 & 100.00 & 0.44 & 228.70 & 56.28 & 0.25 \\
\hline 14 & Hexagon & & 6.20 & $x$ & 6.00 & $x$ & 600.00 & 100.00 & 0.45 & 223.30 & 55.91 & 0.25 \\
\hline 15 & octagon & & 5.28 & $x$ & 6.00 & $x$ & 600.00 & 100.00 & 0.46 & 218.40 & 54.69 & 0.25 \\
\hline 16 & courtyard & & 10.77 & 4.00 & 6.00 & $x$ & 600.00 & 100.00 & 0.28 & 354.50 & 75.23 & 0.21 \\
\hline 17 & Cluster & & 5.00 & 1.50 & 6.00 & $x$ & 600.00 & 100.00 & 0.21 & 480.00 & 95.15 & 0.20 \\
\hline
\end{tabular}

This section discusses basic information of the geometries, such as wall area, wall surface areas, sunlit area of the exterior wall, and two phrases of simulation results based on the models with and without $A / C$ systems.

Building surface functions as an energy exchanging medium between interior and exterior environments. With identical roof surface area $\left(100 \mathrm{~m}^{2}\right)$, construction property $(200 \mathrm{~mm}$ concrete slab), and angle to the sun in all cases (see Fig. 1), the sunlit area and annual solar radiation heat 
gain of each roof are constant at $50.1 \mathrm{~m}^{2}$ and $449780.6 \mathrm{MJ}$, respectively. The wall surface area is considered one of the most influential factors causing excessive heat gain in buildings. Each floor plan may contain a particular layout perimeter which consequently leads to a variation of the wall surface and sunlit areas. The floor, wall surface, and annual average exterior wall areas were observed and simulated, and then were converted into the floor-to-wall area ratio (F/W) and exterior sunlit area-to-wall area ratio (S/W). Fig. 2 demonstrates that each geometry characterizes unique a wall surface area. The figure presents that the wall areas shift from 212.0 for the circular layout to 480.0 for the cluster design. The annual average sunlit area of the exterior wall ranges from $53.1 \mathrm{~m}^{2}$ for circular to $95.2 \mathrm{~m}^{2}$ for the cluster design. The maximum and the minimum floor-towall area ratio (F/W) and annual average wall sunlit area-to-wall area ratio (S/W) are 0.21 to 0.47 for the cluster and circular designs, and 0.20 and 0.25 for the cluster and the other plans (respectively), except for L-shape (0.24) and courtyard (0.21).

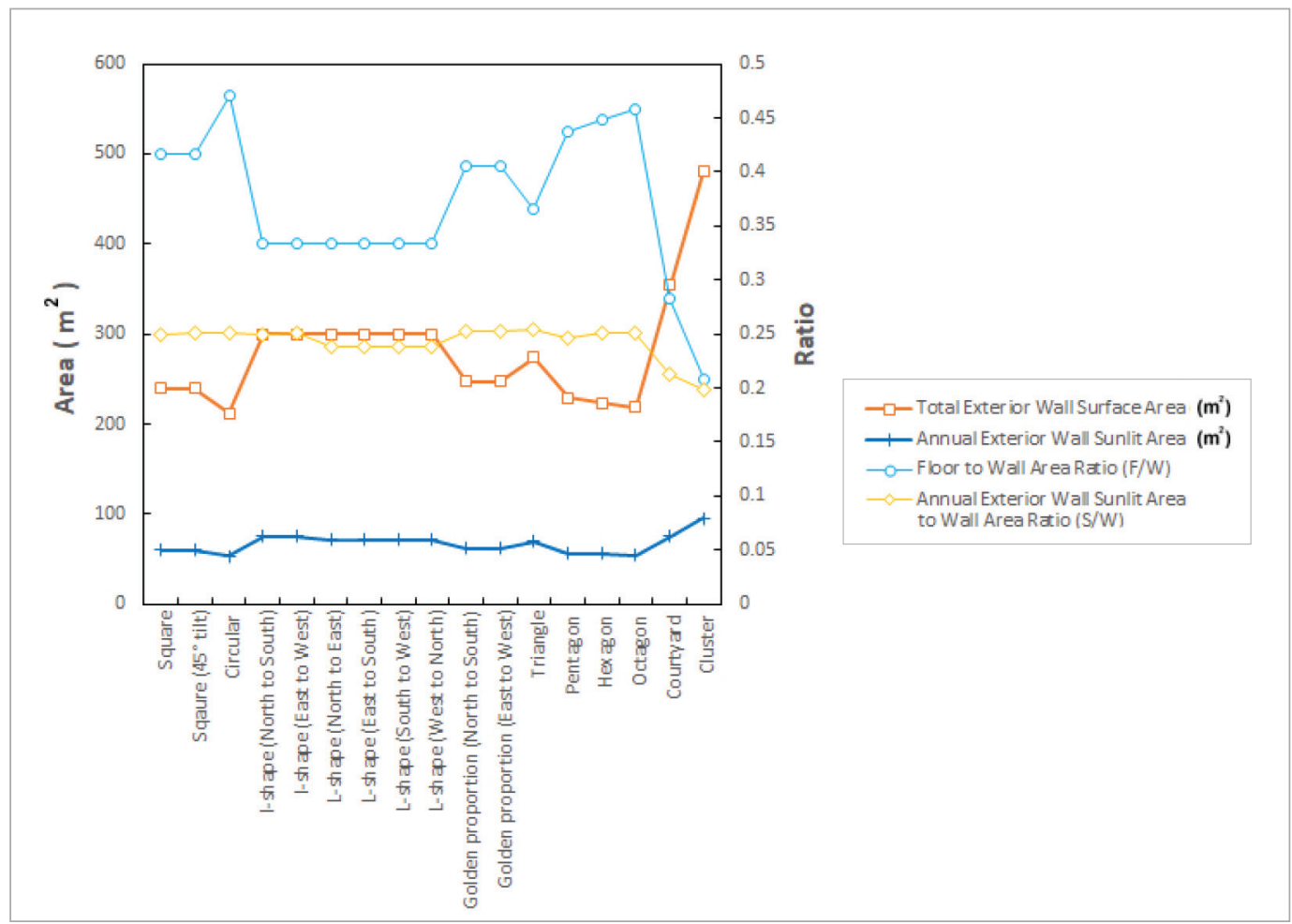

\section{Results for Non-A/C Spaces}

\section{Impact of Environmental Factors on Monthly $\mathrm{DBT}_{\text {indoor }}$ and Solar Radiation on Exterior Wall Surface}

The exterior environment affects the interior thermal condition of the buildings. The outcome of the simulation based on Thailand weather data includes varying DBT indoor of each geometry, differing according to the monthly outdoor DBT (DBT ${ }_{\text {outdoor }}$ ). The minimum and maximum $\mathrm{DBT}_{\text {indoor }}$ are naturally influenced by the outdoor thermal condition of the exterior thermal context. The results show that the I-shape ${ }_{\mathrm{N}-\mathrm{S}}$ is the hottest space for eight months (February to September). The build-

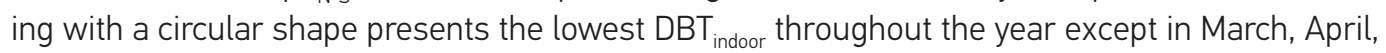
August, and September. Fig. 3 shows the monthly average DBT indoor. The standard deviation (SD) of all cases reports a smaller variation of $\mathrm{DBT}_{\text {indoor }}$ during February to September $(0.09 \leq \mathrm{SD} \leq 0.15)$ than the October to January period $(0.49 \leq \mathrm{SD} \leq 0.53)$.
Fig. 2

Comparison of exterior wall surface and wall sunlit areas and F/W and $\mathrm{S} / \mathrm{W}$ ratios 
Fig. 3

Monthly average DBTindoor of all cases with SD

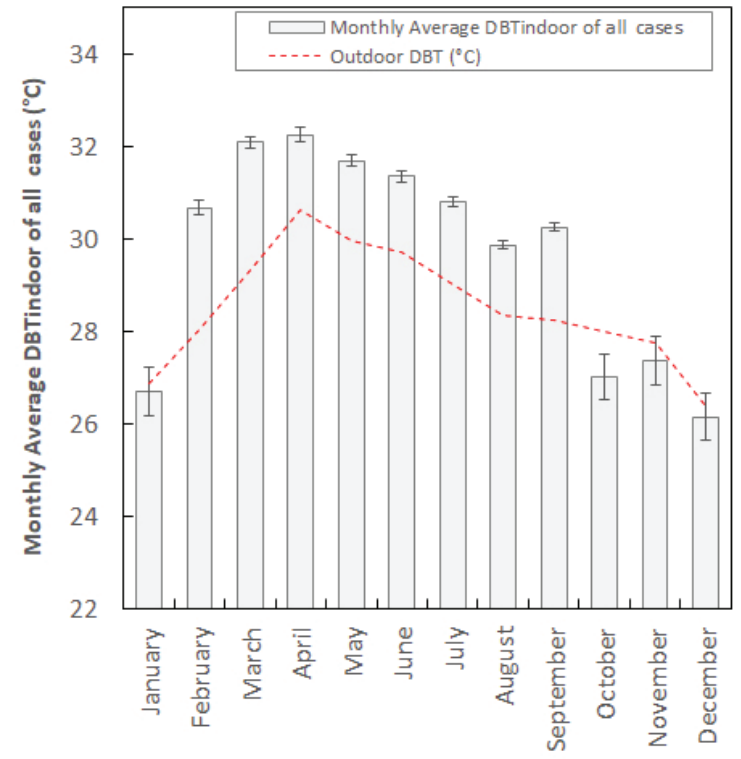

Fig. 4 (left) shows the results of the exterior wall surface area overlaid on DBT indoor-annual, illustrating that $\mathrm{DBT}_{\text {indoor-annual }}$ varies according to geometries and their orientations. The cluster and I-shaped $\mathrm{N}_{\mathrm{N}-\mathrm{S}}$ designs share the highest $\mathrm{DBT}_{\text {indoor-annual }}$ at $29.95^{\circ} \mathrm{C}$. These are followed closely by the courtyard with $\mathrm{DBT}_{\text {indor-annual }}$ of $29.88^{\circ} \mathrm{C}$, and the lowest $\mathrm{DBT}_{\text {indoor-annual }}$ is for the circular design $\left(29.43^{\circ} \mathrm{C}\right)$. Building orientation also causes the difference in $\mathrm{DBT}_{\text {indoor-annual, }}$ since the results show a $0.25^{\circ} \mathrm{C}$ difference in $\mathrm{DBT}_{\text {indoor-annual }}$ between the I-shaped $\mathrm{N}_{\mathrm{N}-\mathrm{S}}$ and I-shaped $\mathrm{E}_{\mathrm{E}-\mathrm{w}}$ designs with the same geometries laid on different axes. The circular plan is the coolest space at $29.43^{\circ} \mathrm{C}$. The figure also presents that the magnitude of exterior wall surface areas (the solid red line with circular blocks) varies according to the value of $\mathrm{DBT}_{\text {indoor-annual }}$ of spaces.

Fig. 4

Comparison of annual average DBTindoorannual and exterior wall surface area (left) and linear regression of external wall surface area and DBTindoorannual (right)

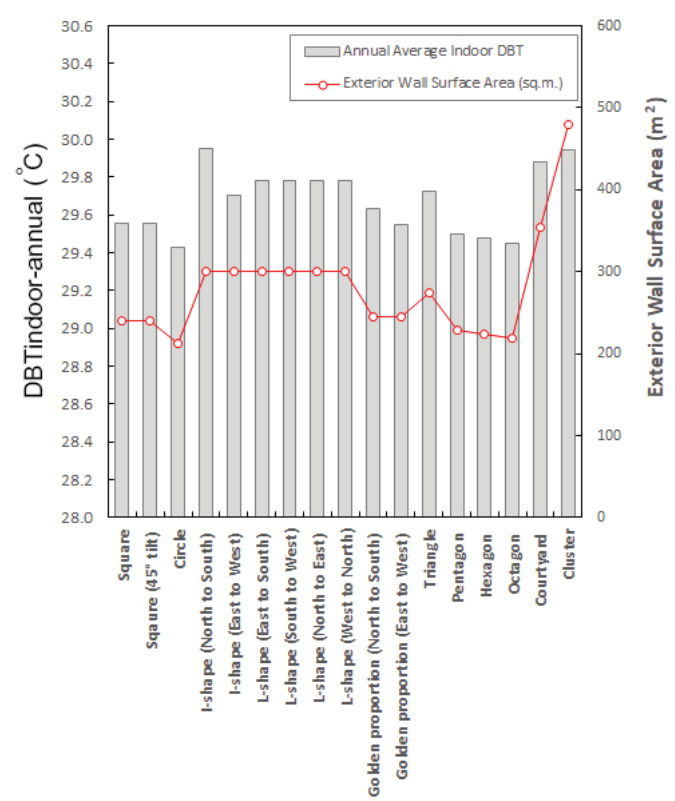


The relationship of these values was examined. Fig. 4 (right) presents a linear regression of $\mathrm{DBT}_{\text {indoor-annual }}$ and exterior wall surface area. The figure shows that the annual average $\mathrm{DBT}_{\text {indor-annual }}$ of each space coincided with a total wall surface area, demonstrating the correlation coefficient (R) of $\mathrm{DBT}_{\text {indoor-annual }}$ with a surface area at 0.71 . The significance level of the coefficient factor of the wall surface area reports a p-value less than $0.01(p<0.01)$. The relationship between the factors can be expressed as in Eq. (2), indicating that an increase in building wall surface area slightly elevates $\mathrm{DBT}_{\text {indoor-annual }}$

$$
\mathrm{DBT}_{\text {indor-annual }}=0.002 \text {. Wall Surface Area }+29.15(\mathrm{R}=0.71, \mathrm{p}<0.01)
$$

Fig. 5 (left) shows that the cluster design, which had the lowest F/W ratio (0.21), had joint-first

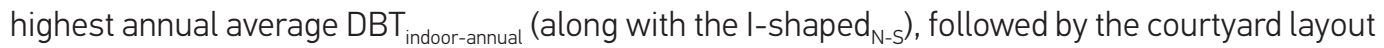
with 0.28 of $\mathrm{F} / \mathrm{W}$ ratio and $\mathrm{DBT}_{\text {indoor-annual }}$ of $29.88^{\circ} \mathrm{C}$.

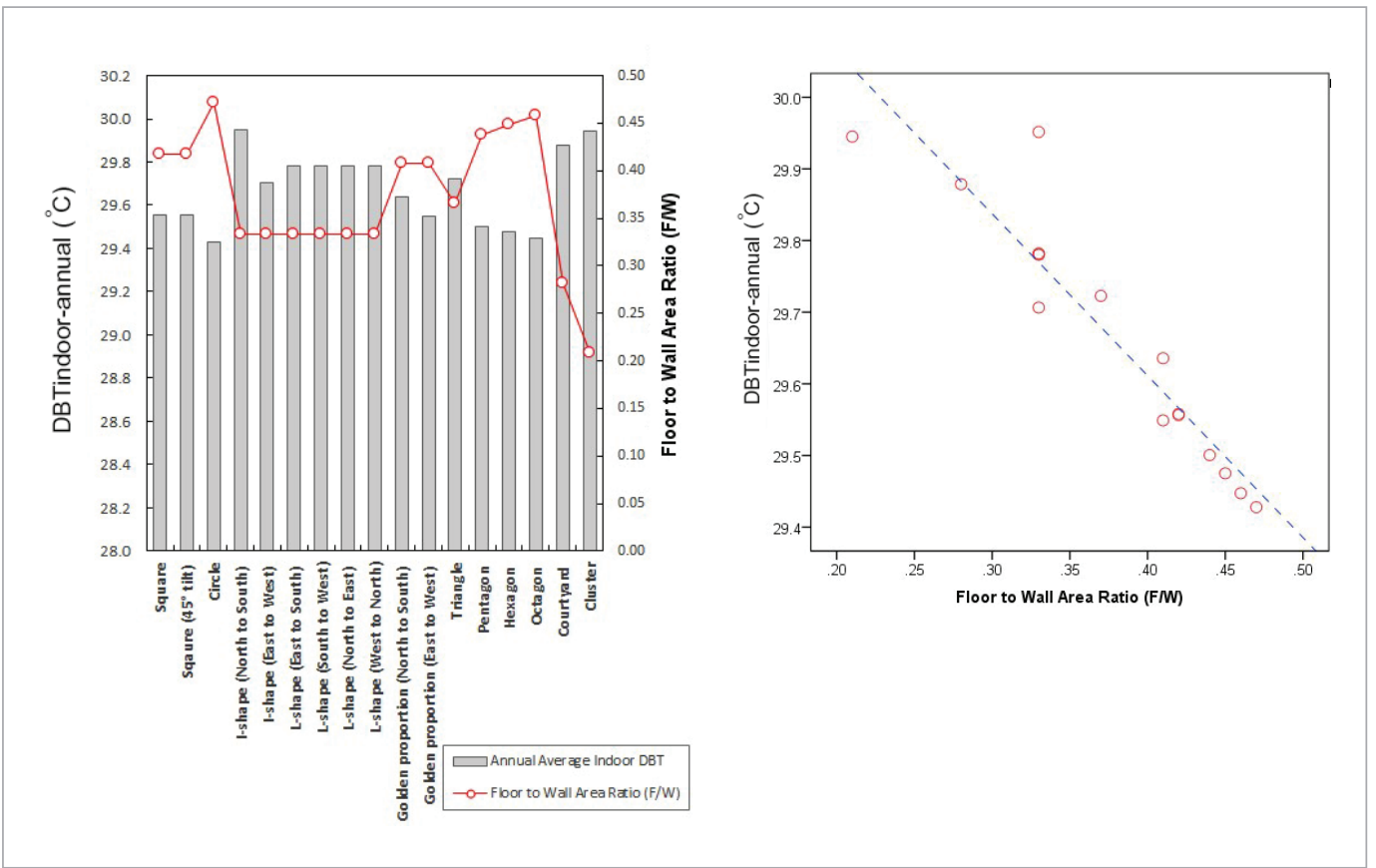

The relationship of DBT indoor-annual and F/W was examined. Fig. 5 (right) demonstrates a relationship between $\mathrm{F} / \mathrm{W}$ and annual average $\mathrm{DBT}_{\text {indoor-annual }}$ with $\mathrm{R}$ of 0.94 ; the significance level of the independent variable is less than $0.01(p<0.01)$, as Eq. 3 expresses. This model allows building designers to estimate the indoor impact due to the building layout using the F/W ratio in the early design stage (which has important implications for project management life cycle). The lower the F/W ratio is, the higher the expected $\mathrm{DBT}_{\text {indoor-annual }}$.

$$
\mathrm{DBT}_{\text {indoor-annual }}=-2.259 . \mathrm{F} / \mathrm{W}+30.515(\mathrm{R}=0.94, \mathrm{p}<0.01)
$$

Results of the annual average heat gain rate show concordant results with the $\mathrm{DBT}_{\text {indoor-annual }}$ and F/W. The cluster design with the F/W ratio of 0.21 received the highest annual solar radiation, accounting for approximately $765944.4 \mathrm{MJ}$ per year. Similarly, the highest F/W ratio was found with the circular plan, which had the minimal annual heat gain (448564.1 MJ per year), as Fig. 6 presents.
Fig. 5

Comparison (left) and regression (right) of DBTindoor-annual and F/W 
Fig. 6

Comparison of $\mathrm{F} / \mathrm{W}$, $\mathrm{S} / \mathrm{W}$, and wall solar heat gain energy

Fig. 7

Regression of wall solar radiation heat gain (MJ) and F/W

ratio
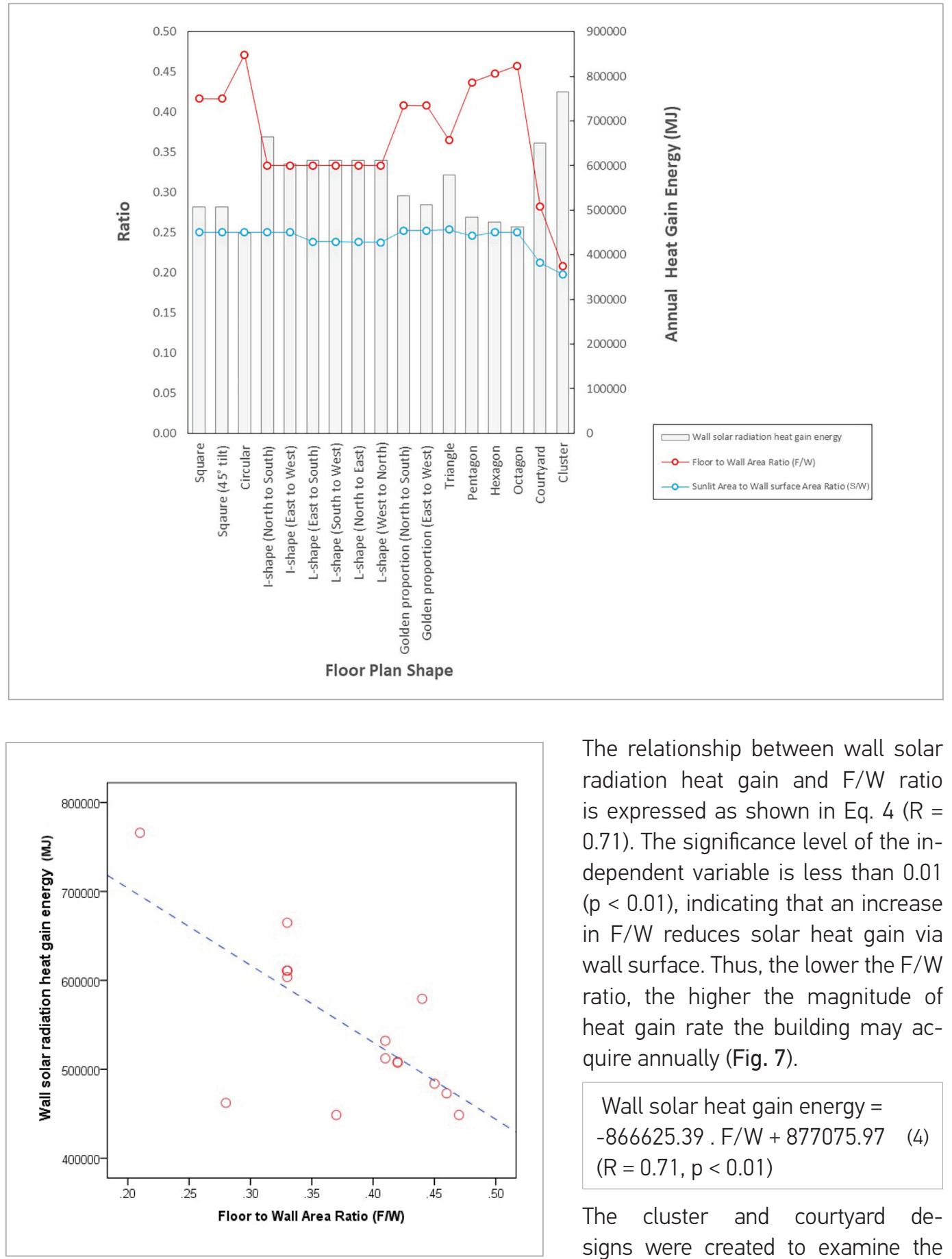

The relationship between wall solar radiation heat gain and $\mathrm{F} / \mathrm{W}$ ratio is expressed as shown in Eq. $4(\mathrm{R}=$ 0.71 ). The significance level of the independent variable is less than 0.01 $(p<0.01)$, indicating that an increase in $\mathrm{F} / \mathrm{W}$ reduces solar heat gain via wall surface. Thus, the lower the F/W ratio, the higher the magnitude of heat gain rate the building may acquire annually (Fig. 7).

Wall solar heat gain energy $=$

$-866625.39 . F / W+877075.97 \quad$ (4)

$(\mathrm{R}=0.71, \mathrm{p}<0.01)$

The cluster and courtyard designs were created to examine the self-shading design in decreasing the amount of solar gain of the building surface. The cluster design has the greatest annual average exterior sunlit area with the lowest S/W ratio, indicating that the wall surface of this building is more extensively shaded than the other geometries. However, it should be noted that the self-shading cluster and the courtyard designs may not perform better in decreasing indoor air temperature. Although this technique allows the cluster and courtyard plans to be shaded by their mass, avoiding the receipt of more direct solar beam radiation (Fig. 8), it entails disadvantages regarding its longer building perimeter, creating a more extensive wall surface. This increment of wall surface leads to an opportunity for receiving a greater amount of sky and ground diffuse radiation. 


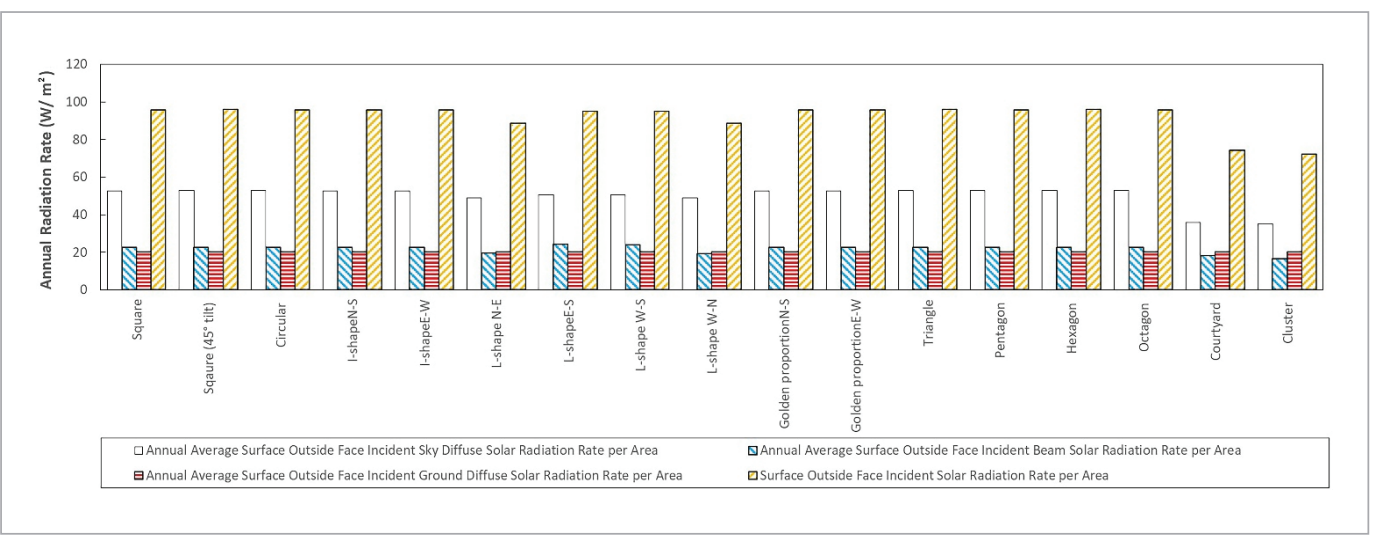

Fig. 8

Annual radiation rates of wall

surfaces

\section{The Impact of Geometries on Sensible Cooling Consumption}

This section discusses the results of the models with a unitary $A / C$ system. Fig. 9 presents the monthly average $\mathrm{DBT}_{\text {indor }}$ after operating the $\mathrm{A} / \mathrm{C}$ system. The results show that the spaces are under $25^{\circ} \mathrm{C}$ controlled by the thermostat throughout the year. Such a constant temperature maintained over the hot period is subject to the sensible cooling energy by the active cooling system.
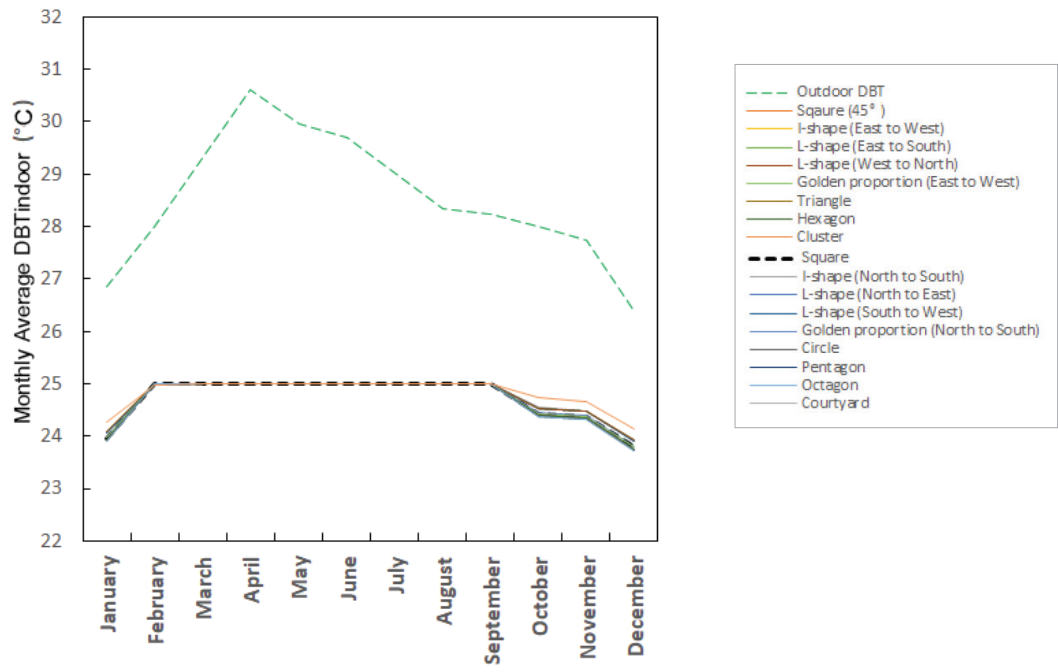

Fig. 9

Monthly DBTindoor of each building layout when operating the $\mathrm{A} / \mathrm{C}$ system

The amount of annual air sensible cooling energy overlaid over the F/W ratio, as shown in Fig. 10, is similar to the results in Fig. 5 (left) and Fig. 6, exhibiting the role of the wall surface area as a factor influencing the DBT indoor and surface heat gain. Likewise, the amount of energy served to the $\mathrm{A} / \mathrm{C}$ system also varies according to the wall surface factor. The figure shows that the cluster design may be the most energy-demanding layout for the air sensible cooling system compared to the other approaches. In contrast, the circular design may require the least amount of energy to serve the $A / C$ system under the same floor area and volume.

The correlation of $A / C$ energy consumption and wall surface area additionally presents a strong relationship between the factors ( $R=0.97)$, as Eq. 5 expresses. The significance level of the independent variable is less than $0.00(p<0.01)$, indicating that a change of the wall area relates to an increase in annual energy consumption $\mathrm{A} / \mathrm{C}$ system. 
Fig. 10

Annual air sensible cooling energy and F/W ratio (left) and their relation (right)

\section{Fig. 11}

Comparison of the percentage of energy saving compared to the benchmark geometry (square shape)

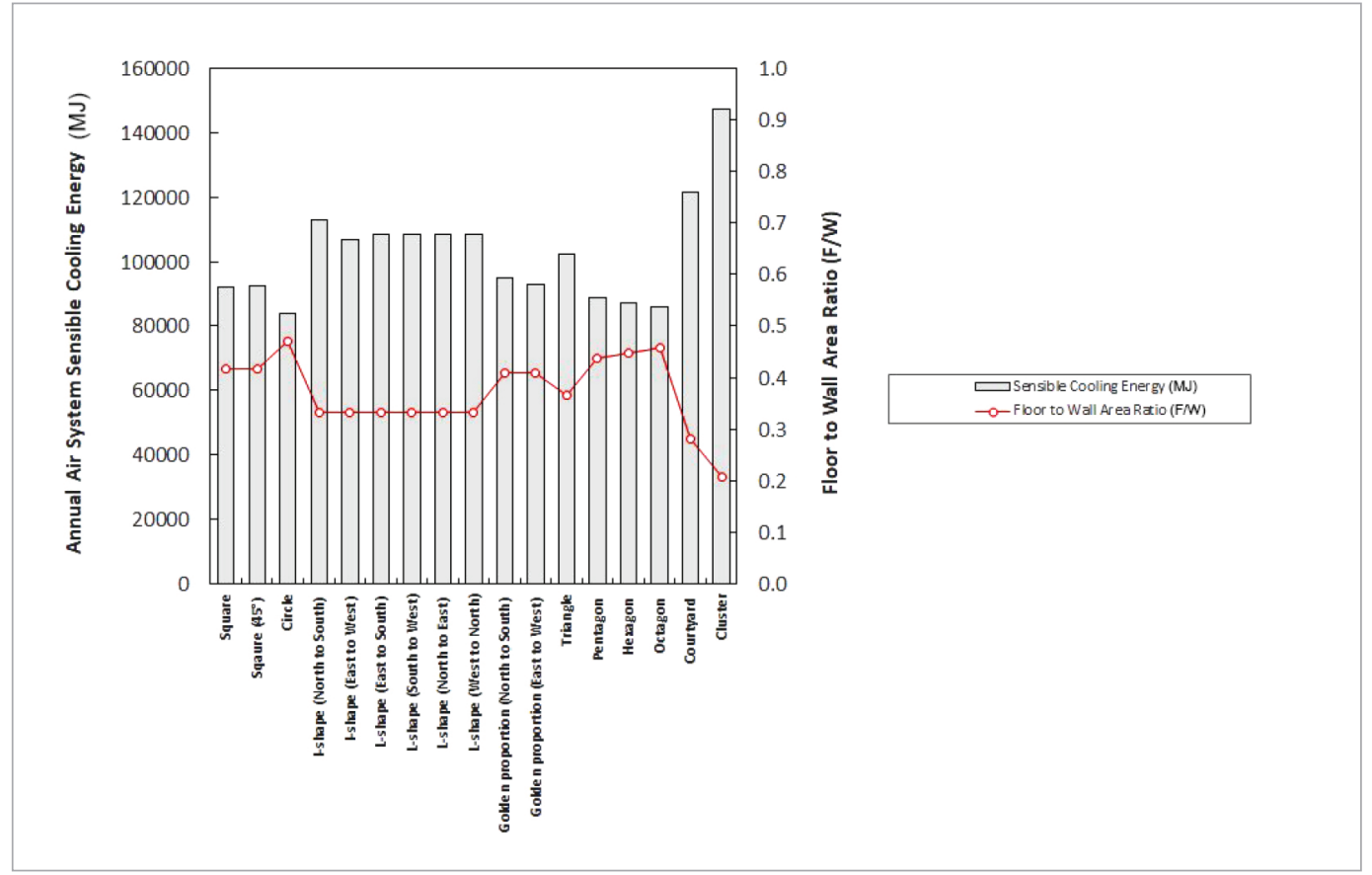

To investigate the amount of energy-saving each layout can perform, the benchmark building, the air sensible cooling energy of the benchmark building (the square plan) is compared. The results are reported as a percentage saving, as shown in Fig. 11 presents. The operational costs of the 12 cases are higher than the baseline building, but compared to the benchmark design, cooling energy loads are reduced in the other designs, specifically by: $3.6 \%$ in the pentagonal, $5.4 \%$ in the hexagonal, $7.2 \%$ in the octagonal, and $9.9 \%$ in the circular designs. 
The results of this study must be seen in terms of the interplay between traditional vernacular design and modern energy needs. Modern construction technology dictates that standard modern Thai architecture is premised on the use of A/C systems, with relatively air-tight and compact spaces to maintain the standard setpoint temperature. This is fundamentally different from the traditional Thai cluster design, with everyday life mainly lived on a charn which is an elevated terrace space clustered and shaded by enclosed functions. The cluster floor plan aims to promote natural ventilation into the charn and allow the enclosed functions to extend their wall surface area to create cross-ventilation, which is a crucial cooling technique for hot and humid architecture. The buildings are built with lightweight materials such as timber and bamboo, with low thermal mass and high infiltration, aiming to define spaces, but not to confine and store heat.

Typically, domestic buildings in Thailand have thinner walls $(100 \mathrm{~mm})$ than those built to withstand the extremely cold or hot climates. This passive design technique, using low thermal mass property with high value of infiltration and natural ventilation, become the default construction mode, transferred from one generation to another. Hot and humid climates are buffered from extremes of heat and cold, and year-round vegetation help block heat and reduce direct solar gain. Traditionally, tropical peoples lived interdependently with their natural environment, and developed their architecture according to their local climatic and cultural conditions.

Deciding on suitable layouts was an early process of architectural design that affected the longterm thermal condition of buildings. According to the results, if the space volume and floor area are controlled, wall surface area may influence the amount of heat gain of the building. The smaller the $\mathrm{F} / \mathrm{W}$ value is, the lower $\mathrm{DBT}_{\text {indor-annual }}$ and air sensible cooling energy can be expected. The design with self-shading features, such as L-shape, courtyard, and cluster layouts, may present $\mathrm{S} / \mathrm{W}$ values of less than 2.5 . Smaller $\mathrm{S} / \mathrm{W}$ ratios represent a minimum sunlit area compared to the whole wall surface of the geometry. In this regard, it can be noticed that although the design aims to minimize the sunlit area by extending and folding floor plan perimeter, the building may face challenges with higher wall surface area.

These results lead to a reconsideration of adopting self-shading mass, such as courtyard and cluster designs, due to their relatively poor performance in $\mathrm{DBT}_{\text {indoor-annual }}$ reduction (compared to other layouts). S/W of 2.5 may be considered as a benchmark to classify the characteristic of self-shading design of layouts. Buildings without self-shading strategies may present $\mathrm{S} / \mathrm{W}$ ratios higher than 2.5, while the self-shading geometries such as L-shape, courtyard, and cluster layouts may show S/W lower than 2.5. The shading feature creates the shaded wall surface, which decreases the area of direct solar radiation. The longer building perimeter of the courtyard and cluster layouts causes an elevation of wall surface area, which tends to increase the chance to receive a greater amount of diffuse solar radiation. The recent results under the hot and humid climate justify why the courtyard layout requires a higher air cooling energy, and shows accordance with the study of Hatem and Karram (2020) under hot and dry climate conditions.

This study reveals that the cluster design with low S/W (0.20) may no longer be the best strategy for air-conditioned space, since the cluster design entails a greater wall area, which leads to low F/W $(0.21)$ ratio. The linear regression model of $\mathrm{F} / \mathrm{W}$ and $\mathrm{DBT}_{\text {indoor-annual }}$ (see $\mathrm{Eq} .3$ ) indicates that every 1.0 F/W increase results in a $2.3^{\circ} \mathrm{C}$ reduction of $\mathrm{DBT}_{\text {indor-annual }}$. The cluster layout shares the highest $\mathrm{DBT}_{\text {indor-annual }}$ with I-shape $\mathrm{N}-\mathrm{S}_{\text {of }} 29.95^{\circ} \mathrm{C}$, while that of the square and circular designs present 29.56 and $29.43^{\circ} \mathrm{C}$, respectively. Therefore, in the modern era, where buildings are generally equipped with $\mathrm{A} / \mathrm{C}$ systems, a compact design with low $\mathrm{F} / \mathrm{W}$ with minimum wall surface may be preferable. Besides, this study found that the low S/W value may entail the higher wall surface area, which increases heat gain by solar radiation. 
Besides, the results of this study affirm those of Chenvidyakarn (2007), who recommended that rectangular shapes should orient the smallest area of wall surface to the strongest solar radiation (along the east-west axis). This was corroborated by this study's findings that DBTindoor-annual of I-shape $\mathrm{E}_{\mathrm{W}}\left(29.71^{\circ} \mathrm{C}\right)$ and $\operatorname{Golden}_{\mathrm{E}-\mathrm{W}}\left(29.55^{\circ} \mathrm{C}\right)$ are lower than I-shape $\mathrm{N}-\mathrm{S}\left(29.95^{\circ} \mathrm{C}\right)$ and Golden $\mathrm{N}_{\mathrm{N}-\mathrm{S}}\left(29.64^{\circ} \mathrm{C}\right)$.

Deciding on suitable building layouts can reduce undesirable impacts on indoor temperature and decrease the amount of energy consumption caused by active cooling. EnergyPlus simulation based on Bangkok weather data to examine 17 models with floor plan areas and volumes, controlled at $100 \mathrm{~m}^{2}$ and $600 \mathrm{~m}^{3}$, respectively, yielded the following main conclusions:

_ Building layout shapes change total external wall surface area, thereby fundamentally affecting energy consumption and indoor thermal condition.

_ The orientation of long and narrow building layouts is sensitive to solar radiation. A building designed with such characteristics pays close attention to orientation to minimize solar gain. The I-shape $\mathrm{E}_{\mathrm{E}-\mathrm{W}}$ layout features a lower $\mathrm{DBT}_{\text {indoor-annual }}$ compared to the I-shape $\mathrm{N}-\mathrm{S}_{\text {, which has }}$ implications for planning location and layout relative to the sun-path direction.

- The total exterior wall area of the building can be considered as a contributing factor influencing $\mathrm{DBT}_{\text {indoor }}$ which has implications for sensible air cooling energy in buildings. Minimizing wall surface area or maximizing the $\mathrm{F} / \mathrm{W}$ ratio may lower the $\mathrm{DBT}_{\text {indoor-annual }}$ and $\mathrm{A} / \mathrm{C}$ system operational costs.

- The maximum $\mathrm{DBT}_{\text {indoor-annual }}$ difference among the layouts $\left(0.52^{\circ} \mathrm{C}\right)$ confirms that building layouts exert a substantive influence on indoor thermal condition and air cooling energy demand.

- Compared with the other floor plan shapes, the circular and octagon layouts demonstrate the lowest $\mathrm{DBT}_{\text {indoor-annual }}\left(29.43\right.$ and $29.45^{\circ} \mathrm{C}$, respectively), which is attributable to minimized exterior wall surface areas.

_- The hottest $\mathrm{DBT}_{\text {indoor-annual }}\left(29.95^{\circ} \mathrm{C}\right)$ is shared between the cluster and I-shape ${ }_{\mathrm{N}-\mathrm{S}}$ layouts, followed by the courtyard design $\left(29.88^{\circ} \mathrm{C}\right)$. These types of layout show the highest energy demand for annual sensible cooling energy accounting.

Simple layout designs tend to be fully exposed to solar radiation. The self-shading cases present a lower S/W compared to fully sun-exposed building design. The cluster design with the 1.5-m-width corridor, the courtyard, and the L-shape layouts showed self-shading features of exterior walls, characterizing smaller annual average S/W ratios of $0.20,0.21$, and 0.24 , respectively. In contrast, the other non-self-shading cases demonstrate an equal $\mathrm{S} / \mathrm{W}$ value of 0.25 .

- The cluster and courtyard layouts seem to perform less effectively in lowering the $\mathrm{DBT}_{\text {indoor-annual }}$ and active cooling energy demand than the other cases. Although the aim of reducing the S/W ratio using this self-shading design may decrease the amount of received beam radiation, the building may face the challenge of external heat gain. An increase in the area of the building perimeter elevates the wall surface area, which results in receiving a greater amount of diffuse solar radiation from the sky and ground.

This study reveals the environmental impacts on indoor thermal condition and active cooling energy utilization over a year based on the algorithm of the simulation engine. A laboratory study is recommended to explore more precise experimental quantification with the same controlled variables, to verify the derived results. 
Al Ka'bi, A.H. Comparison of Energy Simulation Applications Used in Green Building. Annales Des Telecommunications/Annals of Telecommunications, 2020; 75 (7-8), 271-290. https://doi.org/10.1007/ s12243-020-00771-6

Al-Hafith, O., Satish, B.K., Bradbury, S., and De Wilde, P. The Impact of Courtyard Parameters on Its Shading Level An Experimental Study in Baghdad, Iraq. Energy Procedia, 2017; 134, 99-109. https:// doi.org/10.1016/j.egypro.2017.09.539

Chenvidyakarn, T. Review Article: Passive Design for Thermal Comfort in Hot Humid Climates. Journal of Architectural/Planning Research and Studies, 2007; 5 (1), 1-28. available from <http://www.tds. tu.ac.th/jars/download/jars/v5-1/01 Review Article.pdf>.

DEDE. Openstudio Program. 2017; available from http://dede-peecb.bright-ce.com/Simulation Models/Program.html.

Energyplus. Weather Data by Region. 2021; available from https://energyplus.net/weather-region/ asia_wmo_region_2/THA.

Fanger, P.O. Thermal Comfort. Copenhagen. Danish Technical Press; 1979.

Ferdous, T. and Gorgolewski, M. Determining the Effect of Building Geometry on Energy Use Patterns of Office Buildings in Toronto. Journal of Green Building, 2014; 9 (2), 124-144.https://doi. org/10.3992/1943-4618-9.2.124

Fosdick, J. and Homes, T.C. Passive Solar Heating. 2016; available from <https://www.wbdg.org/resources/passive-solar-heating $>$.

FSEC Energy Research Centre. How to Reduce Energy Costs in Existing Homes - Priorities, 2019; available from <https://energyresearch.ucf.edu/ consumer/buildings/priorities/>.

Goia, F. Search for the Optimal Window-to-Wall Ratio in Office Buildings in Different European Climates and the Implications on Total Energy Saving Potential. Solar Energy, 2016; 132, 467-492, available from <https://www.sciencedirect.com/science/article/pii/S0038092X16002188>. https://doi. org/10.1016/j.solener.2016.03.031

Hatem, H.M. and Karram, M.A. Integrating Layout Geometry with Architectural Requirements to Achieve Energy-Efficient Office Buildings in Egypt, 2020; 610-617. available from <https://www. ashrae.org/file library/conferences/specialty conferences/2020 building performance/papers/dbsc20-c074.pdf>.

Jeyasingh, V. and Sekar, S.P. Thermal Performance of Naturally Ventilated Residential Building with Various Room Orientations in The Hot-Humid Cli- mate of Chenai, India. Journal of Architecture and Planing Research, 2013; 30 (1), 1-22. available from https://www.jstor.org/stable/43030990.

Jitkhajornwanich, K. Recommendations for Climate-Response Architecture for Hot and Humid Climate. NAJUA: Architecture, Design and Built Environment, 2001; 17, 169-176. available from <https:// so04.tci-thaijo.org/index.php/NAJUA-Arch/article/ view/45877>.

Liu, S., Kwok, Y.T., Lau, K.K.L., Chan, P.W., and Ng, E. Investigating the Energy Saving Potential of Applying Shading Panels on Opaque Façades: A Case Study for Residential Buildings in Hong Kong. Energy and Buildings, 2019; 193, 78-91. https://doi. org/10.1016/j.enbuild.2019.03.044

Panitchpakdi, K. Transfer of the Cultural Heritage of the Traditional Thai House: Usiri Family Houses. Environment-Behaviour Proceedings Journal, 2016; 1 (3), 237. ttps://doi.org/10.21834/e-bpj.v1i3.368

Parasonis, J., Keizikas, A., and Kalibatiene, D. The Relationship between the Shape of a Building and Its Energy Performance. Architectural Engineering and Design Management, 2012; 8 (4), 246-256. https://doi.org/10.1080/17452007.2012.675139

Petersen, S. and Purup, P.B. Building Performance Simulation Supporting Typical Design Activities: The Case of "Reference Pictures". Building Simulation Conference Proceedings, 2019; 4 (September 2020), 2591-2597.

Soflaei, F., Shokouhian, M., Abraveshdar, H., and Alipour, A. The Impact of Courtyard Design Variants on Shading Performance in Hot- Arid Climates of Iran. Energy and Buildings, 2017; 143, 71-83. https://doi. org/10.1016/j.enbuild.2017.03.027

Su, B. Building Passive Design and Housing Energy Efficiency. Architecturak Review, 2008; 51 (3). https://doi.org/10.3763/asre.2008.5133

Susorova, I., Tabibzadeh, M., Rahman, A., Clack, H.L., and Elnimeiri, M. The Effect of Geometry Factors on Fenestration Energy Performance and Energy Savings in Office Buildings. Energy and Buildings, 2013; 57, 6-13. https://doi.org/10.1016/j.enbuild.2012.10.035

U.S. Department of Energy. EnergyPlusTM Version 9.5.0 Documentation Engineering Reference. 2021; available from <https://energyplus.net/sites/all/ modules/custom/nrel_custom/pdfs/pdfs_v9.2.0/ EngineeringReference.pdf>.

Zhang, A., Bokel, R., van den Dobbelsteen, A., Sun, Y., Huang, Q., and Zhang, Q. The Effect of Geometry Parameters on Energy and Thermal Performance of School Buildings in Cold Climates of China, 2017; Sustainability (Switzerland) 9 (10). https://doi. org/10.3390/su9101708
References 
About the Author

\section{THANUN SRITHONGCHAI}

\section{Lecturer}

Faculty of Architecture, Khon Kaen University, Thailand

\section{Main research area}

Specialized in human thermal comfort study focusing on adaptive approach.

Personal interest is in passive design for improving users' wellbeing

\section{Address}

Faculty of Architecture Khon Kaen University.

Mittraphab Highway, Khon Kaen, 40002 Thailand.

Tel. 043306376 Fax. 043306374.

E-mail: Thanunsri@kku.ac.th or Thanun_Srithongchai@hotmail.com 